\title{
Preoperative Neutrophil-to-lymphocyte Ratio May Predict Postoperative Pneumonia in Stage I-III Gastric Cancer Patients After Curative Gastrectomy: A Retrospective Study
}

\section{Mikito Mori ( $\nabla$ mikimori45@yahoo.co.jp )}

Ichikawa Hospital

\section{Kiyohiko Shuto}

Teikyo University Chiba Medical Center

\section{Atsushi Hirano}

International University of Health and Welfare Ichikawa Hospital

\section{Kazuo Narushima}

International University of Health and Welfare Ichikawa Hospital

\section{Chihiro Kosugi}

Teikyo University Chiba Medical Center

\section{Masato Yamazaki}

Teikyo University Chiba Medical Center

\section{Keiji Koda}

Teikyo University Chiba Medical Center

\section{Masahiro Yoshida \\ International University of Health and Welfare Ichikawa Hospital}

\section{Research article}

Keywords: Gastric cancer, Neutrophils, Lymphocytes, C-reactive protein, Serum albumin, Postoperative complications

Posted Date: August 26th, 2020

DOI: https://doi.org/10.21203/rs.3.rs-60453/v1

License: (a) (i) This work is licensed under a Creative Commons Attribution 4.0 International License. Read Full License

Version of Record: A version of this preprint was published at World Journal of Surgery on July 31st, 2021. See the published version at https://doi.org/10.1007/s00268-021-06264-4. 


\section{Abstract}

Background: Several studies have demonstrated that diverse systemic inflammatory-based prognostic parameters predict poor prognosis in patients with gastric cancer. However, few studies focused on the relationships between postoperative complications and systemic inflammatory-based prognostic parameters after curative gastrectomy. We investigated the relationships between postoperative complications and these parameters to identify parameter-specific postoperative complications, and assessed the clinical utility of the parameters as predictors of postoperative complications in stage I-III gastric cancer patients.

Methods: We retrospectively reviewed 300 patients who underwent curative gastrectomy for stage I- III gastric cancer. A postoperative complication sensitive to the systemic inflammatory-based prognostic parameters was identified using a receiver operating characteristic curve, and we evaluated the relationships between the identified postoperative complication and other clinical factors.

Results: In total, 101 patients (33.7\%) had postoperative Clavien-Dindo grade II-IV complications, namely anastomotic complications, such as leak, stenosis, or hemorrhage (35 patients, $11.7 \%$ ); pancreatic fistula (16 patients, 5.3\%); and pneumonia (14 patients, 4.7\%). Postoperative pneumonia had the most sensitive relationship to five systemic inflammatory-based prognostic parameters, and was associated with poor prognosis in stage I-III gastric cancer patients after curative gastrectomy. Multivariate analysis revealed that preoperative neutrophil-to-lymphocyte ratio (odds ratio: 5.228, 95\% confidence interval: 1.269-21.541; $P=0.022$ ) was an independent predictor of postoperative pneumonia.

Conclusions: Preoperative neutrophil-to-lymphocyte ratio may be a useful predictor of postoperative pneumonia in stage I-III gastric cancer patients after curative gastrectomy.

\section{Background}

Although the incidence of gastric cancer (GC) has been decreasing, GC remains an intractable disease worldwide because it is the fifth most frequently diagnosed cancer and the third leading cause of cancer death [1]. Generally, gastrectomy with prophylactic lymph node dissection plays a pivotal role in the treatment of stage I-III GC patients [2]. Although marked advancements in GC surgery have occurred, further decrease in the incidence of postoperative complications after curative gastrectomy is still required because the onset or progression of postoperative complications may prolong hospitalization, impair quality of life, and worsen prognosis in GC patients [3-8]. Therefore, the relationships between postoperative complications and various patient, operation, or cancer-related factors have been evaluated to identify useful predictors of postoperative complications after gastrectomy [7-10].

Systemic inflammatory-based prognostic parameters, such as the neutrophil-to-lymphocyte ratio (NLR), platelet-to-lymphocyte ratio (PLR), prognostic nutrition index (PNI), and C-reactive protein-to-albumin ratio (CAR) are well-known predictors of poor prognosis in GC patients [11-16]. Recently, some studies proposed that these parameters were associated with not only poor prognosis but also with postoperative complications in GC patients [15-19]. Furthermore, Okugawa et al [18] identified lymphocyte-to-C-reactive protein ratio (LCR) before surgery as a promising new marker for surgical and oncological outcomes in stage 
I-IV GC patients. However, previous studies assessed the relationship between one systemic inflammatorybased prognostic parameter and all postoperative complications or surgical site infections [15-19], and few studies thoroughly assessed the relationships between multiple systemic inflammatory-based prognostic parameters and postoperative complications in stage I-III GC patients after curative gastrectomy [19]. Therefore, we investigated the relationships between postoperative complications and the representative systemic inflammatory-based prognostic parameters to identify a specific postoperative complication sensitive to the systemic inflammatory-based prognostic parameter, and assessed the clinical utility of the parameter as a predictor of postoperative complications in stage I-III GC patients after curative gastrectomy.

\section{Methods}

\section{Patients}

We retrospectively reviewed the electronic medical records of 300 patients who underwent curative gastrectomy with D1+ or D2 lymph node dissection between January 2006 and December 2019 at the International University of Health and Welfare Ichikawa Hospital and Teikyo University Chiba Medical Center, Japan. The patient inclusion criteria were as follows: age $\geq 20$ years, elective operation for GC, and histologically-confirmed diagnosis of stage I, II, or III GC. We excluded patients who received neoadjuvant chemotherapy or radiotherapy, had acute infectious or inflammatory diseases, GC combined with other malignancies, or ventilator-associated pneumonia. Pathological staging was performed according to the cancer staging system for GC recommended in the 8th edition of the American Joint Committee on Cancer Staging Manual [20]. All patients provided informed written consent, and the study protocol was approved by the Institutional Review Boards in all participating institutions.

\section{Calculating the systemic inflammatory-based prognostic parameters}

A routine blood examination was performed within 1 week before surgery. We selected preoperative NLR, PLR, PNI, CAR, and LCR as the representative systemic inflammatory-based prognostic parameters, in this study. As previously reported, NLR or PLR was calculated by dividing the neutrophil or platelet count, respectively, by the lymphocyte count, and PNI was calculated as the sum of the lymphocyte count multiplied by 0.005 and serum albumin multiplied by 10 . In addition, CAR was calculated by dividing serum C-reactive protein (CRP) concentration by the albumin concentration, and LCR was calculated by dividing CRP by the lymphocyte count [11-19].

\section{Definition of postoperative complications}

All postoperative complications were graded using the Clavien-Dindo classification system [21]. When an anastomotic leak, stenosis, or hemorrhage was suspected, upper gastrointestinal endoscopy and computed tomography (CT) were performed to confirm these complications. Anastomotic leak, stenosis, or hemorrhage was defined as anastomotic complication in this study. Postoperative pancreatic fistula was diagnosed when the amylase concentration in the abdominal drainage fluid was three times higher than the upper limit of the normal serum value on the third day after gastrectomy [22]. Postoperative pneumonia was diagnosed according to postoperative radiological and clinical findings, with chest X-ray or CT examinations showing 
new or progressive and consistent infiltration, opacity or consolidation, and cavitation. Clinical confirmation required one of the following conditions: body temperature $\geq 38^{\circ} \mathrm{C}$, new or progressive and continuous coughing and expectoration with abnormal white blood cell counts ( $<.0$ or $\geq 12.0 \times 10^{9} / \mathrm{L}$ ), or positive respiratory cultures from sputum or blood [23,24]. A diagnosis of postoperative ileus was based on the patient's symptoms, and abdominal X-ray and CT findings. Chyle leak or chylous ascites was defined as > $200 \mathrm{~mL}$ per day of milky white fluid discharge with a triglyceride content of at least $110 \mathrm{mg} / \mathrm{dL}$ [25]. Remnant gastric stasis was defined as remnant stomach stasis when a patient with postprandial nausea, vomiting, and other symptoms of gastric stasis had no anastomotic stenosis, intestinal obstruction, and abdominal infection. Supra- or ventricular arrhythmia was defined as cardiac complication.

\section{Statistical Analysis}

The relationships between the postoperative complications and the systemic inflammatory-based prognostic parameters were evaluated by the area under the curves (AUCs) of the receiver operating characteristic (ROC) curves. Overall survival (OS) or relapse-free survival (RFS) curves were generated using the Kaplan-Meier method, and univariate analysis of OS or RFS was performed using Cox regression analysis and the log-rank test. Univariate analyses of postoperative complications were performed using logistic regression to determine the statistical significance between the clinical factors and the postoperative complications identified by the ROC curve analyses. $P$ values in multiple comparisons were corrected using a false discovery rate. Multivariate analysis was performed using logistic regression to determine the statistical significance of the clinical factors identified by univariate analysis. $P$ values $<0.05$ indicated statistical significance. All statistical analyses were performed using SPSS for Windows (version 26.0; IBM Corp., Armonk, NY, USA).

\section{Results}

\section{Patients' characteristics}

The clinical characteristics of the 300 patients (77 women, 223 men) with stage I- III GC who underwent curative gastrectomy are summarized in Table 1. The median age was 70 years (range: $36-95$ years), and the median body mass index was $21.9 \mathrm{~kg} / \mathrm{m}^{2}$ (range: $14.8-37.2 \mathrm{~kg} / \mathrm{m}^{2}$ ). Fifty-five patients had diabetes mellitus, 44 patients had cardiac comorbidities, and 16 patients had pulmonary comorbidities. The surgical approaches were as follows: 187 patients underwent distal gastrectomy, 97 underwent total gastrectomy, and 16 underwent proximal gastrectomy. The median operative time was $277 \mathrm{~min}$ (range: 85-822 min), and the median estimated blood loss was $178 \mathrm{~mL}$ (range: 5-4031 mL). One hundred thirty-five patients, 74 patients, or 91 patients were diagnosed with pathological stage I, II, or III GC, respectively. The median preoperative NLR, PLR, PNI, CAR, and LCR were 2.3 (range: 0.4-18.7), 140.0 (range: 31.3-555.3), 50.1 (range: 30.2-68.7), 0.05 (range: 0.02-3.68), and 8501 (range: 134-51392), respectively.

\section{Relationships between postoperative complications and the systemic inflammatory-based prognostic parameters in stage I-III GC patients}


One hundred and one patients (33.7\%) developed a postoperative complication of Clavien-Dindo grade II-IV. Thirty-five patients $(11.7 \%)$ developed anastomotic complications, namely leak (14 patients, $4.7 \%$ ), stenosis (15 patients, $5.0 \%)$, or hemorrhage ( 6 patients, $2.0 \%$ ). Sixteen patients $(5.3 \%)$ had pancreatic fistula, 14 patients $(4.7 \%)$ had pneumonia, and 10 patients $(3.0 \%)$ had ileus (Table 2$)$.

To evaluate the relationships between each postoperative complication and preoperative NLR, PLR, PNI, CAR, or LCR, all systemic inflammatory-based prognostic parameters were assessed using ROC curves. For all postoperative complications, the AUCs for preoperative NLR, PLR, PNI, CAR, or LCR were 0.599, 0.527, 0.477, 0.545 , or 0.471 , respectively. For the anastomotic complications, the AUCs for preoperative NLR, PLR, PNI, CAR, or LCR were $0.446,0.412,0.534,0.514$, or 0.520 , respectively. For pancreatic fistula, the AUCs for preoperative NLR, PLR, PNI, CAR, or LCR were $0.744,0.696,0.414,0.485$, or 0.504 , respectively. Interestingly, the AUCs for preoperative NLR, PLR, PNI, CAR, or LCR for postoperative pneumonia were $0.817,0.704,0.252$, 0.729 , or 0.276 , respectively, and postoperative pneumonia was the most sensitive parameter related to preoperative NLR, PLR, PNI, CAR, or LCR (Table 2). Therefore, postoperative pneumonia was identified as the postoperative complication closely related to the systemic inflammatory-based prognostic parameters. Using the ROC curves, the cutoff value for preoperative NLR, PLR, PNI, CAR, or LCR was set at 2.9 (sensitivity, 78.6\%; specificity, 70.6\%), 154.8 (sensitivity, 71.4\%; specificity, 60.8\%), 47.7 (sensitivity, 64.3\%; specificity, 68.5\%), 0.07 (sensitivity, $71.4 \%$; specificity, $66.4 \%$ ), or 5273 (sensitivity, $71.4 \%$; specificity, $69.9 \%$ ), respectively (Fig. 1).

\section{Relationships between postoperative pneumonia and prognosis in stage I-III GC patients}

The relationships between all postoperative complications and the prognosis of stage I- III GC patients were assessed, and we identified a significant difference between patients with and without any postoperative complication regarding OS ( $P=0.002)$ and RFS $(P=0.013)$ (Fig. 2a and b). We also assessed the relationship between each postoperative complication and the prognosis of stage I-III GC patients. Regarding OS, postoperative pneumonia was the only complication with a significant difference; no significant difference was found for the other complications. Regarding RFS, postoperative pneumonia and pancreatic fistula showed a significant difference (Table 3). Considering each of these findings, postoperative pneumonia was the only complication showing a significant difference for OS $(P<0.001)$ and RFS $(P=0.009)$, and also affected the prognosis of stage I-III GC patients (Fig. 3a and b).

\section{Identifying a useful predictor of postoperative pneumonia in stage I-III GC patients}

To identify useful predictors for postoperative pneumonia related to poor prognosis in stage I- III GC patients, 27 clinical factors, including preoperative NLR, PLR, PNI, CAR, and LCR, were assessed using univariate analysis. Statistical significance in multiple comparisons in the univariate analysis was adjusted using a false discovery rate. Univariate analysis after false discovery rate correction showed that preoperative NLR (odds ratio (OR), 8.817; 95\% confidence interval $(\mathrm{Cl}), 2.399-32.409 ; P=0.001)$, preoperative LCR (OR, 0.172; $95 \% \mathrm{Cl}, 0.052-0.564 ; P=0.004)$, and total gastrectomy (OR, 3.284; $95 \% \mathrm{Cl}, 1.513-7.130 ; P=0.003$ ) showed a significant difference. Moreover, multivariate analysis of the three significant factors identified using univariate analysis revealed that preoperative NLR (OR, 5.228; $95 \% \mathrm{Cl}, 1.269-21.541 ; P=0.022)$ and total gastrectomy (OR, 2.824; 95\% Cl, 1.217-6.556; $P=0.016$ ) were independent risk factors for postoperative pneumonia (Table 4). 


\section{Discussion}

We comprehensively assessed the relationships between postoperative complications and systemic inflammatory-based prognostic parameters. We found that postoperative pneumonia was the most sensitive to preoperative NLR, PLR, PNI, CAR, or LCR, and identified preoperative NLR as an independent risk factor for postoperative pneumonia after curative gastrectomy.

Although the mechanism of systemic inflammation in cancer development or progression remains complicated and unclarified, it is certain that systemic inflammation plays a pivotal role. In particular, increased leukocyte or platelet counts, elevated CRP, and hypoalbuminemia are usually observed in the systemic inflammatory response. Systemic inflammation involves circulating cytokines, small inflammatory proteins, circulating immune cells, and acute-phase proteins [26]. Neutrophils, which account for most circulating leukocytes, act as the body's first line of defense against infection or cancer, and platelets release vascular endothelial growth factor and platelet-derived growth factor to mediate the migration and extravasation of leukocytes or to recruit neutrophils and monocytes [27]. In contrast, lymphocytes are involved in suppressing cancer development or progression [28]. CRP and albumin are classified as major plasma proteins and are synthesized in the liver and secreted into the circulation. CRP is a well-known important acute-phase response protein and is one of the most sensitive indicators of inflammation caused by cancer or surgical procedures. Albumin is a main component of human serum total protein, maintaining blood colloid osmotic pressure, transporting metabolites, and reflecting nutritional status [26]. Using combinations of circulating immune cells or acute-phase proteins identified by routine blood examinations, several studies revealed the relationships between poor prognosis of GC patients and inflammation-based markers, such as NLR, PLR, PNI, CAR, or LCR.

Postoperative complications, especially infectious complications, may lead to prolonged inflammation and may eventually affect long-term survival by providing an advantageous microenvironment for cancer progression. Some studies have suggested that the poor prognosis of GC patients was associated with the incidence of postoperative infectious complications $[4,5,15]$. Postoperative pneumonia is considered one of the most common infectious complications after GC surgery. The reported incidence of any postoperative complication after GC surgery ranges from $10.3 \%$ to $44.8 \%$ [3,6-10], and the reported incidence of pneumonia ranges from $1.1 \%$ to $12.3 \%[29,30]$. Our results were comparable to the results of previous studies regarding the incidence of any postoperative complication and the incidence of pneumonia, at $33.7 \%$ and $4.7 \%$, respectively. Some studies indicated a relationship between postoperative pneumonia and poor prognosis of GC patients, and suggested several patient or operation-related risk factors for postoperative pneumonia, such as age, smoking history, pulmonary comorbidities, operative time, and operative procedures in GC surgery [29-32]. Even though there was no significant difference between postoperative pneumonia and age, smoking history, pulmonary comorbidities, or operative time in this study, our results confirmed that total gastrectomy was an independent predictor of postoperative pneumonia in stage I-III GC patients after curative gastrectomy, as previous studies demonstrated.

Recently, several studies have assessed the relationships between postoperative complications and systemic inflammatory-based prognostic parameters in GC patients. Mohri et al [15] revealed that preoperative NLR independently predicted the development of postoperative infectious complications after curative 
gastrectomy, and Kanda et al [16] also showed that preoperative PNI was a significant predictor of postoperative morbidity after curative gastrectomy. Moreover, Toiyama et al [17] suggested that high CAR before GC surgery predicted the incidence of surgical site infections. However, although Inaoka et al [19] demonstrated that preoperative PLR predicted postoperative morbidity compared with other parameters, namely NLR and PNI, few studies have assessed the relationships between postoperative complications and multiple systemic inflammatory-based prognostic parameters, namely NLR, PLR, PNI, CAR, or LCR.

Furthermore, only a few studies of non-small cell lung cancer or meningioma surgery identified preoperative NLR as a predictor of postoperative pneumonia [33,34], and no studies identified preoperative NLR as a predictor of postoperative pneumonia in GC surgery. Therefore, to our knowledge, ours is the first study revealing that preoperative NLR was one of the most useful predictors of postoperative pneumonia in stage I-III GC patients after curative gastrectomy.

Our study has limitations. Because this was a retrospective study involving a relatively small sample size and patient selection bias, there were differences in patients' characteristics, and the difference could have led to biased estimates of prognoses and postoperative complications. Moreover, it is difficult to precisely diagnose when patients with postoperative pneumonia have other complications of different severity and with different impact on prognosis. Although our findings should be interpreted with caution, we believe that their potential clinical significance justifies further investigation.

\section{Conclusion}

Our study demonstrated that preoperative NLR was one of the most useful predictors of postoperative pneumonia in stage I-III GC patients after curative gastrectomy. Although further investigation is required to verify the utility of preoperative NLR as a predictor of postoperative pneumonia in GC patients after curative gastrectomy, high NLR in GC patients before curative gastrectomy may contribute to the prediction or prevention of postoperative pneumonia postoperatively.

\section{Abbreviations}

GC: Gastric cancer; NLR: Neutrophil-to-lymphocyte ratio; PLR: Platelet-to-lymphocyte ratio; PNI: Prognostic nutrition index; CAR: C-reactive protein-to-albumin ratio; LCR: Lymphocyte-to-C-reactive protein ratio; CRP: Creactive protein ratio; $\mathrm{CT}$ : Computed tomography; ROC: Receiver operating characteristic; AUC: Area under the ROC curve; OS: Overall survival; RFS: Relapse-free survival; OR: Odds ratio; Cl: Confidence interval

\section{Declarations}

Ethics approval and consent to participate: The study was conducted in accordance with the principals of the Declaration of Helsinki. The International University of Health and Welfare Ichikawa Hospital (Ethics approval number: No.89), and Teikyo University Chiba Medical Center (Ethics approval number: No.18-171) Ethics Review Boards approved retrospective data collection and analysis.

Consent for publication: Not applicable. 
Availability of data and materials: The datasets used and/or analyzed during the current study are available from the corresponding author upon reasonable request.

Competing interests: The authors declare that they have no competing interests.

Funding: Not applicable.

Authors' contributions: SK, HA, NK, and MM collected the data, KC, YM, and MM performed the statistical analysis, and $\mathrm{YM}, \mathrm{KK}$, and $\mathrm{MM}$ drafted the manuscript. All authors read and approved the final manuscript. All authors read and approved the final manuscript.

\section{Acknowledgments:}

We thank Jane Charbonneau, DVM, from Edanz Group (https://en-author-services.edanzgroup.com/) for editing a draft of this manuscript.

\section{References}

1. Bray F, Ferlay J, Soerjomataram I, Siegel RL, Torre LA, Jemal A. Global cancer statistics 2018: GLOBOCAN estimates of incidence and mortality worldwide for 36 cancers in 185 Countries. CA Cancer J Clin. 2018;68:394-424.

2. Brenkman HJ, Haverkamp L, Ruurda JP, van Hillegersberg R. Worldwide practice in gastric cancer surgery. World J Gastroenterol. 2016;22:4041-

3. Jiang N, Deng JY, Ding XW, Zhang L, Liu HG, Liang YX, et al. Effect of complication grade on survival following curative gastrectomy for carcinoma. World J Gastroenterol. 2014;20:8244-

4. Tokunaga M, Tanizawa Y, Bando E, Kawamura T, Terashima M. Poor survival rate in patients with postoperative intra-abdominal infectious complications following curative gastrectomy for gastric cancer. Ann Surg Oncol. 2013;20:1575-

5. Hayashi T, Yoshikawa T, Aoyama T, Hasegawa S, Yamada T, Tsuchida K, et al. Impact of infectious complications on gastric cancer recurrence. Gastric Cancer. 2015;18:368-

6. Powell A, Coxon AH, Patel N, Chan D, Christian A, Lewis W. Prognostic significance of post-operative morbidity severity score after potentially curative D2 gastrectomy for carcinoma. J Gastrointest Surg. 2018;22:1516-

7. Martin AN, Das D, Turrentine FE, Bauer TW, Adams RB, Zaydfudim VM. Morbidity and mortality after gastrectomy: identification of modifiable risk factors. J Gastrointest Surg. 2016;20:1554-

8. Yuan P, Wu Z, Li Z, Bu Z, Wu A, Wu X, et al. Impact of postoperative major complications on long-term survival after radical resection of gastric cancer. BMC Cancer. 2019;19:833.

9. Jung KH, Kim SM, Choi MG, Lee JH, Noh JH, Sohn TS, et al. Preoperative smoking cessation can reduce postoperative complications in gastric cancer surgery. Gastric Cancer. 2015;18:683-

10. Mori M, Shuto K, Hirano A, Kosugi C, Narushima K, Hosokawa I, et al. A novel parameter identified using indocyanine green fluorescence angiography may contribute to predicting anastomotic leakage in gastric cancer surgery. World J Surg. 2020;44:2699- 
11. Mori M, Shuto K, Kosugi C, Narushima K, Hayashi H, Matsubara H, et al. An increase in the neutrophil-tolymphocyte ratio during adjuvant chemotherapy indicates a poor prognosis in patients with stage II or III gastric cancer. BMC Cancer. 2018;18:1261.

12. Saito H, Kono Y, Murakami Y, Shishido Y, Kuroda H, Matsunaga T, et al. Prognostic significance of platelet-based inflammatory indicators in patients with gastric cancer. World J Surg. 2018;42:2542-

13. Migita K, Takayama T, Saeki K, Matsumoto S, Wakatsuki K, Enomoto K, et al. The prognostic nutritional index predicts long-term outcomes of gastric cancer patients independent of tumor stage. Ann Surg Oncol. 2013;20:2647-

14. Liu X, Sun X, Liu J, Kong P, Chen S, Zhan Y, et al. Preoperative C-reactive protein/albumin ratio predicts prognosis of patients after curative resection for gastric cancer. Transl Oncol. 2015;8:339-

15. Mohri Y, Tanaka K, Toiyama Y, Ohi M, Yasuda H, Inoue Y, et al. Impact of preoperative neutrophil to lymphocyte ratio and postoperative infectious complications on survival after curative gastrectomy for gastric cancer: a single institutional cohort study. Medicine (Baltimore). 2016;95:e3125.

16. Kanda M, Mizuno A, Tanaka C, Kobayashi D, Fujiwara M, Iwata N, et al. Nutritional predictors for postoperative short-term and long-term outcomes of patients with gastric cancer. Medicine (Baltimore). 2016;95:e3781.

17. Toiyama Y, Shimura T, Yasuda H, Fujikawa H, Okita Y, Kobayashi M, et al. Clinical burden of C-reactive protein/albumin ratio before curative surgery for patients with gastric cancer. Anticancer Res. 2016;36:649-

18. Okugawa Y, Toiyama Y, Yamamoto A, Shigemori T, Ichikawa T, Yin C, et al. Lymphocyte-to-C-reactive protein ratio and score are clinically feasible nutrition-inflammation markers of outcome in patients with gastric cancer. Clin Nutr. 2020;39:1209-

19. Inaoka K, Kanda M, Uda H, Tanaka Y, Tanaka C, Kobayashi D, et al. Clinical utility of the plateletlymphocyte ratio as a predictor of postoperative complications after radical gastrectomy for clinical T24 gastric cancer. World J Gastroenterol. 2017;23:2519-

20. Ajani JA, In H, Sano T, Gaspar LE, Erasmus JJ, Tang LH, et al. In: Amin MB, Edge SB, Greene FL, et al., editors. AJCC Cancer Staging Manual, 8th ed. New York: Springer; 2016. p. 203-20.

21. Dindo D, Demartines N, Clavien PA. Classification of surgical complications: a new proposal with evaluation in a cohort of 6336 patients and results of a survey. Ann Surg. 2004;240:205-

22. Bassi C, Dervenis C, Butturini G, Fingerhut A, Yeo C, Izbicki J, et al. Postoperative pancreatic fistula: An International Study Group (ISGPF) Definition. Surgery. 2005;138:8-

23. Kieninger AN, Lipsett PA. Hospital-acquired pneumonia: pathophysiology, diagnosis, and treatment. Surg Clin North Am. 2009;89:439-

24. American Thoracic Society and Infectious Diseases Society of America. Guidelines for the management of adults with hospital-acquired, ventilator-associated, and healthcare-associated pneumonia. Am J Respir Crit Care Med. 2005;171:388-

25. Strobel O, Brangs S, Hinz U, Pausch T, Hüttner FJ, Diener MK, et al. Incidence, risk factors and clinical implications of chyle leak after pancreatic surgery. Br J Surg. 2017;104:108- 
26. Diakos $\mathrm{Cl}$, Charles KA, McMillan DC, Clarke SJ. Cancer-related inflammation and treatment effectiveness. Lancet Oncol. 2014;15:e493-e

27. Rossaint J, Margraf A, Zarbock A. Role of platelets in leukocyte recruitment and resolution of inflammation. Front Immunol. 2018;9:2712.

28. Dunn GP, Old LJ, Schreiber RD. The immunobiology of cancer immunosurveillance and immunoediting. Immunity. 2004;21:137-48.

29. Tu RH, Lin JX, Li P, Xie JW, Wang JB, Lu J, et al. Prognostic significance of postoperative pneumonia after curative resection for patients with gastric cancer. Cancer Med. 2017;6:2757-

30. Xiao H, Zhou H, Liu K, Liao X, Yan S, Yin B, et al. Development and validation of a prognostic nomogram for predicting post-operative pulmonary infection in gastric cancer patients following radical gastrectomy. Sci Rep. 2019;9:14587.

31. Suzuki S, Kanaji S, Matsuda Y, Yamamoto M, Hasegawa H, Yamashita K, et al. Long-term impact of postoperative pneumonia after curative gastrectomy for elderly gastric cancer patients. Ann Gastroenterol Surg. 2017;2:72-

32. Shibata C, Ogawa H, Nakano T, Koyama K, Yamamoto K, Nagao M, et al. Influence of age on postoperative complications especially pneumonia after gastrectomy for gastric cancer. BMC Surg. 2019;19:106.

33. Lan H, Zhou L, Chi D, Zhou Q, Tang X, Zhu D, et al. Preoperative platelet to lymphocyte and neutrophil to lymphocyte ratios are independent prognostic factors for patients undergoing lung cancer radical surgery: a single institutional cohort study. Oncotarget. 2017;8:35301-

34. Zuo MR, Liang RF, Li M, Xiang YF, Zhang SX, Yang Y, et al. A comprehensive study of risk factors for post-operative pneumonia following resection of meningioma. BMC Cancer. 2019;19:100.

\section{Tables}




\begin{tabular}{|c|c|}
\hline Parameter & $N=300$ \\
\hline $\operatorname{Sex}(M / F)$ & $223 / 77$ \\
\hline Age (years) & $70(36-95)$ \\
\hline BMI $\left(\mathrm{kg} / \mathrm{m}^{2}\right)$ & $21.9(14.8-37.2)$ \\
\hline ASA-PS classification (I/II/III) & $42 / 208 / 50$ \\
\hline Smoking history $(+/-)$ & $182 / 118$ \\
\hline Diabetes mellitus (+/-) & $55 / 245$ \\
\hline Cardiac comorbidities (+/-) & $44 / 256$ \\
\hline Pulmonary comorbidities (+/-) & $16 / 284$ \\
\hline preoperative WBC $\left(10^{9} / \mathrm{L}\right)$ & $6.2(2.7-17.3)$ \\
\hline preoperative PLT $\left(10^{9} / \mathrm{L}\right)$ & $239(80-685)$ \\
\hline preoperative ALB (g/dL) & $4.2(2.6-5.2)$ \\
\hline preoperative CRP (mg/dL) & $0.2(0.1-13.8)$ \\
\hline preoperative NLR & $2.3(0.4-18.7)$ \\
\hline preoperative PLR & $140.0(31.3-555.3)$ \\
\hline preoperative PNI & $50.1(30.2-68.7)$ \\
\hline preoperative CAR & $0.05(0.02-3.68)$ \\
\hline preoperative LCR & $8501(134-51392)$ \\
\hline Tumor size $(\mathrm{mm})$ & $43(2-170)$ \\
\hline Tumor location (U/M/L/W) & $66 / 106 / 114 / 14$ \\
\hline Histologic type (Diff/Undiff) & $144 / 156$ \\
\hline pT $(1 / 2 / 3 / 4)$ & $127 / 33 / 74 / 66$ \\
\hline $\mathrm{pN}(0 / 1 / 2 / 3)$ & $161 / 49 / 42 / 48$ \\
\hline pStage (I/II/III) & $135 / 74 / 91$ \\
\hline Approach (OP/LP) & $155 / 145$ \\
\hline Gastrectomy $(\mathrm{D} / \mathrm{T} / \mathrm{P})$ & $187 / 97 / 16$ \\
\hline Adjacent organ resection (+/-) & $32 / 268$ \\
\hline OPT (min) & $277(85-822)$ \\
\hline $\mathrm{EBL}(\mathrm{mL})$ & $178(5-4031)$ \\
\hline
\end{tabular}




\begin{tabular}{|c|c|}
\hline Postoperative complications $\geq$ C-D II (+/-) & $101 / 199$ \\
\hline Reoperation (+/-) & $10 / 290$ \\
\hline Adjuvant chemotherapy (+/-) & $126 / 174$ \\
\hline Recurrence (+/-) & $60 / 240$ \\
\hline Outcomes (D/A) & $68 / 232$ \\
\hline \multicolumn{2}{|c|}{ Data are presented as $\mathrm{n}$ (number) or median (range) } \\
\hline \multicolumn{2}{|c|}{$\begin{array}{l}\text { GC, gastric cancer; M, male; F, female; BMI, body mass index; ASA-PS, American Society of } \\
\text { Anesthesiologists physical status; WBC, white blood cell count; PLT, platelet count; ALB, albumin; CRP, C- } \\
\text { reactive protein; NLR, neutrophil-to-lymphocyte ratio; PLR, platelet-to-lymphocyte ratio; PNI, prognostic } \\
\text { nutrition index; CAR, C-reactive protein-to-albumin ratio; LCR, lymphocyte-to-C-reactive protein ratio; U, } \\
\text { upper stomach; M, mid-stomach; L, lower stomach; W, whole stomach; Diff, differentiated; Undiff, } \\
\text { undifferentiated; pT, pN, pStage = pathological T stage, N stage, cancer stage according to the 8th edition } \\
\text { of the American Joint Committee on Cancer (AJCC) Cancer Staging Manual; OP, open gastrectomy; LP, } \\
\text { laparoscopic gastrectomy; D, distal; T, total; P, proximal; OPT, operative time; EBL, estimated blood loss; } \\
\text { C-D, Clavien-Dindo classification; D/A, dead or alive }\end{array}$} \\
\hline
\end{tabular}


Table 2. Relationships between postoperative complications and the representative parameters in GC patients

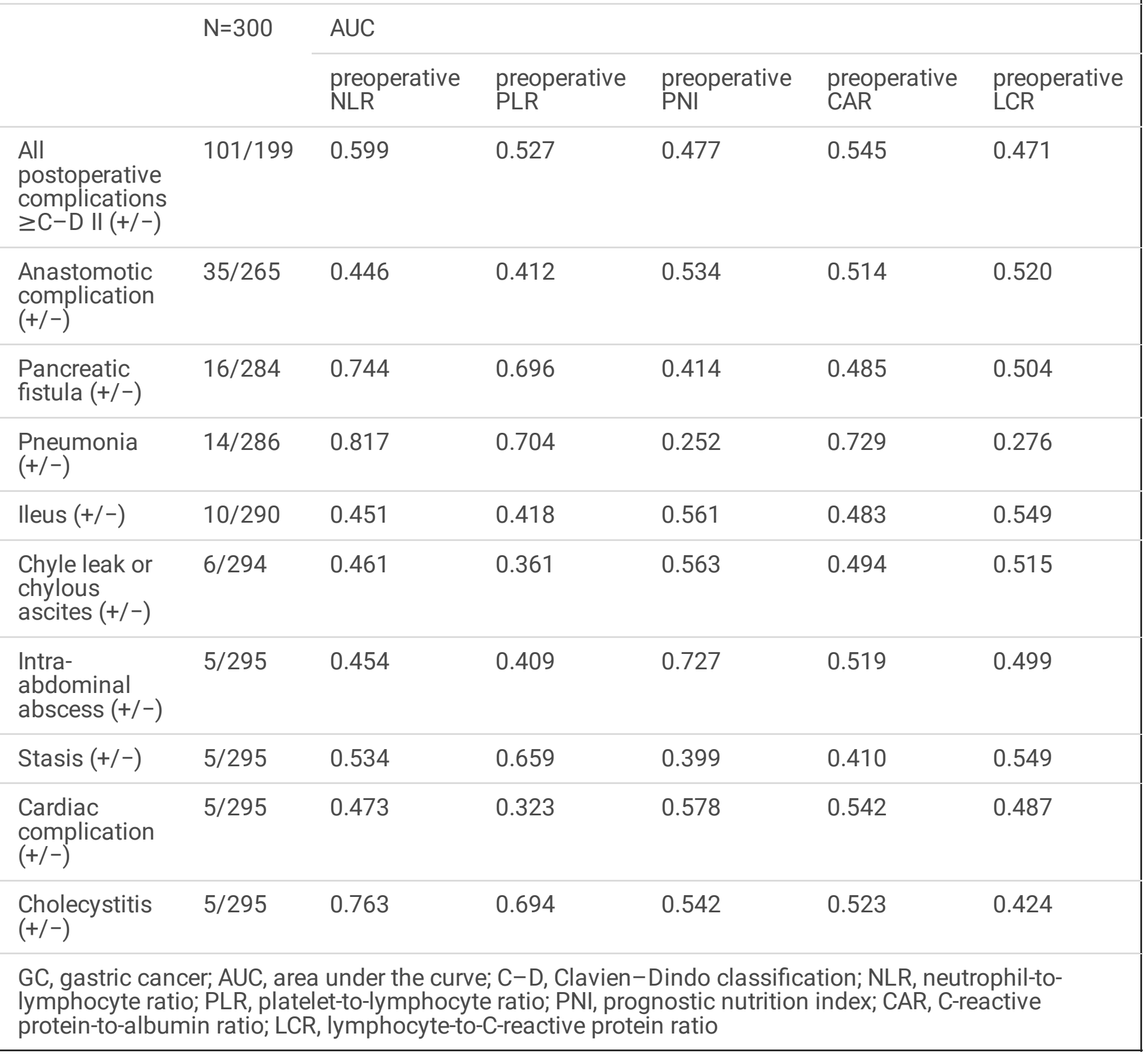




\begin{tabular}{|c|c|c|c|c|c|}
\hline & \multirow[t]{2}{*}{$N=300$} & \multicolumn{2}{|l|}{ OS } & \multicolumn{2}{|l|}{ RFS } \\
\hline & & $\operatorname{HR}(95 \% \mathrm{Cl})^{\mathrm{a}}$ & $\begin{array}{l}p- \\
\text { value }^{b}\end{array}$ & $\operatorname{HR}(95 \% \mathrm{Cl})^{\mathrm{a}}$ & $\begin{array}{l}p- \\
\text { value }^{b}\end{array}$ \\
\hline $\begin{array}{l}\text { Postoperative complications } \\
\geq C-D \|(+/-)\end{array}$ & $101 / 199$ & $\begin{array}{l}2.120(1.313- \\
3.423)\end{array}$ & $0.002^{\star}$ & $\begin{array}{l}1.883(1.133- \\
3.128)\end{array}$ & $0.013^{*}$ \\
\hline Anastomotic complication (+/-) & $35 / 265$ & $\begin{array}{l}1.861(0.974- \\
3.553)\end{array}$ & 0.056 & $\begin{array}{l}1.386(0.658- \\
2.920)\end{array}$ & 0.388 \\
\hline Pancreatic fistula (+/-) & $16 / 284$ & $\begin{array}{l}1.224(0.445- \\
3.372)\end{array}$ & 0.695 & $\begin{array}{l}2.521(1.145- \\
5.550)\end{array}$ & $0.017 *$ \\
\hline Pneumonia (+/-) & $14 / 286$ & $\begin{array}{l}3.759(1.860- \\
7.597)\end{array}$ & $<0.001^{*}$ & $\begin{array}{l}2.946(1.265- \\
6.862)\end{array}$ & $0.009 *$ \\
\hline Ileus $(+/-)$ & $10 / 290$ & $\begin{array}{l}1.268(0.398- \\
4.036)\end{array}$ & 0.687 & $\begin{array}{l}0.452(0.063- \\
3.264)\end{array}$ & 0.419 \\
\hline $\begin{array}{l}\text { Chyle leak or chylous ascites (+/ } \\
-)\end{array}$ & $6 / 294$ & $\begin{array}{l}0.630(0.087- \\
4.543)\end{array}$ & 0.644 & $\begin{array}{l}1.717(0.419- \\
7.031)^{-}\end{array}$ & 0.447 \\
\hline Intra-abdominal abscess (+/-) & $5 / 295$ & $\begin{array}{l}1.285(0.314- \\
5.254)\end{array}$ & 0.726 & $\begin{array}{l}0.794(0.110- \\
5.732)\end{array}$ & 0.819 \\
\hline Stasis (+/-) & $5 / 295$ & $\begin{array}{l}0.710(0.098- \\
5.120)\end{array}$ & 0.733 & $\begin{array}{l}0.835(0.116- \\
6.031)\end{array}$ & 0.858 \\
\hline Cardiac complication (+/-) & $5 / 295$ & $\begin{array}{l}1.719(0.420- \\
7.034)\end{array}$ & 0.446 & $\begin{array}{l}2.258(0.551- \\
9.247)\end{array}$ & 0.244 \\
\hline Cholecystitis (+/-) & $5 / 295$ & $\begin{array}{l}0.689(0.095- \\
4.970)\end{array}$ & 0.710 & $\begin{array}{l}0.048(0.000- \\
168.371)\end{array}$ & 0.273 \\
\hline \multicolumn{6}{|c|}{$\begin{array}{l}\mathrm{GC} \text {, gastric cancer; C-D, Clavien-Dindo classification; OS, overall survival; RFS, relapse-free survival; HR, } \\
\text { hazard ratio; } \mathrm{Cl} \text {, confidence interval; * } p \text { value indicates statistical significance; }{ }^{2} \text { Cox proportional hazards } \\
\text { model; bLog-rank test }\end{array}$} \\
\hline
\end{tabular}




\begin{tabular}{|c|c|c|c|c|c|c|}
\hline \multirow[b]{2}{*}{ Parameter } & \multicolumn{2}{|c|}{ Postoperative pneumonia } & \multicolumn{2}{|c|}{ Univariate analysis } & \multicolumn{2}{|c|}{$\begin{array}{l}\text { Multivariate } \\
\text { analysis }\end{array}$} \\
\hline & + & - & $\begin{array}{l}\text { OR }(95 \% \\
\mathrm{Cl})^{\mathrm{a}}\end{array}$ & $\begin{array}{l}p- \\
\text { value }^{a}\end{array}$ & $\begin{array}{l}\text { OR }(95 \% \\
\mathrm{Cl})^{\mathrm{a}}\end{array}$ & $\begin{array}{l}p- \\
\text { value }\end{array}$ \\
\hline $\operatorname{Sex}(M / F)$ & $10 / 4$ & $213 / 73$ & $\begin{array}{l}1.167 \\
(0.355- \\
3.835)\end{array}$ & 0.799 & & \\
\hline Age (years) $(<70 / \geq 70)$ & $4 / 10$ & $135 / 151$ & $\begin{array}{l}2.235 \\
(0.685- \\
7.292)\end{array}$ & 0.183 & & \\
\hline $\operatorname{BMI}\left(\mathrm{kg} / \mathrm{m}^{2}\right)(<25 / \geq 25)$ & $12 / 2$ & $234 / 52$ & $\begin{array}{l}0.750 \\
(0.163- \\
3.453)\end{array}$ & 0.712 & & \\
\hline $\begin{array}{l}\text { ASA-PS classification } \\
(\mathrm{I} / \mathrm{II} / \mathrm{III})\end{array}$ & $1 / 9 / 4$ & $41 / 199 / 46$ & $\begin{array}{l}0.194 \\
(0.720- \\
5.029)\end{array}$ & 0.194 & & \\
\hline Smoking history (+/-) & $8 / 6$ & $174 / 112$ & $\begin{array}{l}0.858 \\
(0.290- \\
2.539)\end{array}$ & 0.782 & & \\
\hline Diabetes mellitus (+/-) & $3 / 11$ & $52 / 234$ & $\begin{array}{l}1.227 \\
(0.331- \\
4.555)\end{array}$ & 0.760 & & \\
\hline $\begin{array}{l}\text { Cardiac comorbidities (+/ } \\
-)\end{array}$ & $4 / 10$ & $40 / 246$ & $\begin{array}{l}2.460 \\
(0.736- \\
8.223)\end{array}$ & 0.144 & & \\
\hline $\begin{array}{l}\text { Pulmonary comorbidities } \\
(+/-)\end{array}$ & $3 / 11$ & $13 / 273$ & $\begin{array}{l}5.727 \\
(1.423- \\
23.054)\end{array}$ & 0.014 & & \\
\hline $\begin{array}{l}\text { preoperative WBC }\left(10^{9} / \mathrm{L}\right) \\
(<6.5 / \geq 6.5)\end{array}$ & $5 / 9$ & $169 / 117$ & $\begin{array}{l}2.600 \\
(0.850- \\
7.955)\end{array}$ & 0.094 & & \\
\hline $\begin{array}{l}\text { preoperative PLT }\left(10^{9} / \mathrm{L}\right) \\
(<250 / \geq 250)\end{array}$ & $6 / 8$ & $175 / 111$ & $\begin{array}{l}2.102 \\
(0.710- \\
6.220)\end{array}$ & 0.180 & & \\
\hline $\begin{array}{l}\text { preoperative ALB }(\mathrm{g} / \mathrm{dL}) \\
(<4.0 / \geq 4.0)\end{array}$ & $9 / 5$ & $84 / 202$ & $\begin{array}{l}0.231 \\
(0.075- \\
0.710)\end{array}$ & 0.011 & & \\
\hline $\begin{array}{l}\text { preoperative CRP }(\mathrm{mg} / \mathrm{dL}) \\
(<0.3 / \geq 0.3)\end{array}$ & $4 / 10$ & $159 / 127$ & $\begin{array}{l}3.130 \\
(0.959- \\
10.214)\end{array}$ & 0.059 & & \\
\hline $\begin{array}{l}\text { preoperative NLR (<2.9 / } \\
\geq 2.9)\end{array}$ & $3 / 11$ & $202 / 84$ & $\begin{array}{l}8.817 \\
(2.399- \\
32.409)\end{array}$ & $0.001^{*}$ & $\begin{array}{l}5.228 \\
(1.269- \\
21.541)\end{array}$ & 0.022 \\
\hline
\end{tabular}




\begin{tabular}{|c|c|c|c|c|c|c|}
\hline $\begin{array}{l}\text { preoperative PLR (<154.8 } \\
/ \geq 154.8)\end{array}$ & $4 / 10$ & $174 / 112$ & $\begin{array}{l}3.884 \\
(1.189- \\
12.685)\end{array}$ & 0.025 & & \\
\hline $\begin{array}{l}\text { preoperative PNI (<47.7 / } \\
\geq 47.7)\end{array}$ & $9 / 5$ & $90 / 196$ & $\begin{array}{l}0.255 \\
(0.083- \\
0.783)\end{array}$ & 0.017 & & \\
\hline $\begin{array}{l}\text { preoperative CAR }(<0.07 \text { / } \\
\geq 0.07)\end{array}$ & $4 / 10$ & $190 / 96$ & $\begin{array}{l}4.948 \\
(1.512- \\
16.187)\end{array}$ & 0.008 & & \\
\hline $\begin{array}{l}\text { preoperative LCR (<5273 / } \\
\geq 5273)\end{array}$ & $10 / 4$ & $86 / 200$ & $\begin{array}{l}0.172 \\
(0.052- \\
0.564)\end{array}$ & $0.004^{\star}$ & & \\
\hline $\begin{array}{l}\text { Tumor size }(\mathrm{mm})(<45 / \\
\geq 45)\end{array}$ & $4 / 10$ & $150 / 136$ & $\begin{array}{l}2.757 \\
(0.845- \\
8.996)\end{array}$ & 0.093 & & \\
\hline $\begin{array}{l}\text { Histologic type } \\
\text { (Diff/Undiff) }\end{array}$ & $7 / 7$ & 137/149 & $\begin{array}{l}0.919 \\
(0.314- \\
2.689)\end{array}$ & 0.878 & & \\
\hline pT (1/2/3/4) & $3 / 2 / 5 / 4$ & $124 / 31 / 69 / 62$ & $\begin{array}{l}1.375 \\
(0.879- \\
2.153)\end{array}$ & 0.163 & & \\
\hline $\mathrm{pN}(0 / 1 / 2 / 3)$ & $5 / 3 / 1 / 5$ & $156 / 46 / 41 / 43$ & $\begin{array}{l}1.439 \\
(0.934- \\
2.218)\end{array}$ & 0.099 & & \\
\hline pStage (I/II/III) & $5 / 3 / 6$ & $130 / 71 / 85$ & $\begin{array}{l}1.360 \\
(0.730- \\
2.534)\end{array}$ & 0.333 & & \\
\hline Approach (OP/LP) & $13 / 1$ & $142 / 144$ & $\begin{array}{l}0.076 \\
(0.010- \\
0.588)\end{array}$ & 0.014 & & \\
\hline Gastrectomy (D/T/P) & $2 / 11 / 1$ & 185/86/15 & $\begin{array}{l}3.284 \\
(1.513- \\
7.130)\end{array}$ & $0.003^{\star}$ & $\begin{array}{l}2.824 \\
(1.217- \\
6.556)\end{array}$ & 0.016 \\
\hline $\begin{array}{l}\text { Adjacent organ resection } \\
(+/-)\end{array}$ & $4 / 10$ & $28 / 258$ & $\begin{array}{l}3.686 \\
(1.084- \\
12.526)\end{array}$ & 0.037 & & \\
\hline OPT $(\min )(<240 / \geq 240)$ & $7 / 7$ & $74 / 212$ & $\begin{array}{l}0.349 \\
(0.118- \\
1.028)\end{array}$ & 0.056 & & \\
\hline $\operatorname{EBL}(m L)(<300 / \geq 300)$ & $7 / 7$ & $181 / 105$ & $\begin{array}{l}4.310 \\
(1.319- \\
14.084)\end{array}$ & 0.016 & & \\
\hline \multicolumn{7}{|c|}{$\begin{array}{l}\text { GC, gastric cancer; M, male; F, female; BMI, body mass index; ASA-PS, American Society of } \\
\text { Anesthesiologists physical status; WBC, white blood cell count; PLT, platelet count; ALB, albumin; CRP, C- } \\
\text { reactive protein; NLR, neutrophil-to-lymphocyte ratio; PLR, platelet-to-lymphocyte ratio; PNI, prognostic } \\
\text { nutrition index; CAR, C-reactive protein-to-albumin ratio; LCR, lymphocyte-to-C-reactive protein ratio; U, } \\
\text { upper stomach; M, mid-stomach; L, lower stomach; W, whole stomach; Diff, differentiated; Undiff, }\end{array}$} \\
\hline
\end{tabular}


undifferentiated; $\mathrm{pT}, \mathrm{pN}$, pStage = pathological T stage, $\mathrm{N}$ stage, cancer stage according to the 8th edition of the American Joint Committee on Cancer (AJCC) Cancer Staging Manual; OP, open gastrectomy; LP, laparoscopic gastrectomy; D, distal; $T$, total; P, proximal; OPT, operative time; EBL, estimated blood loss; $\mathrm{OR}$, odds ratio; $\mathrm{Cl}$, confidence interval; * $p$ value indicates statistical significance after false discovery rate correction; ${ }^{a}$ Logistic regression

\section{Figures}
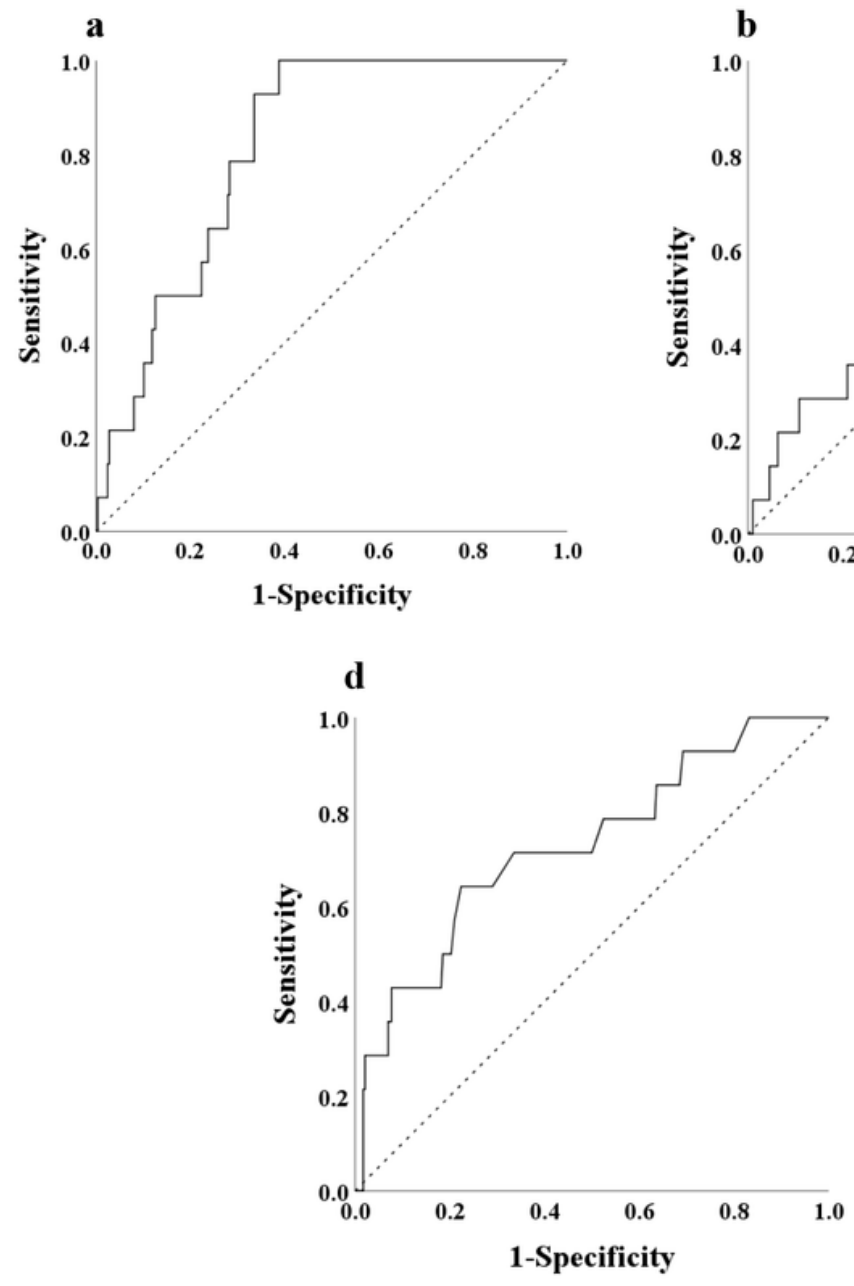
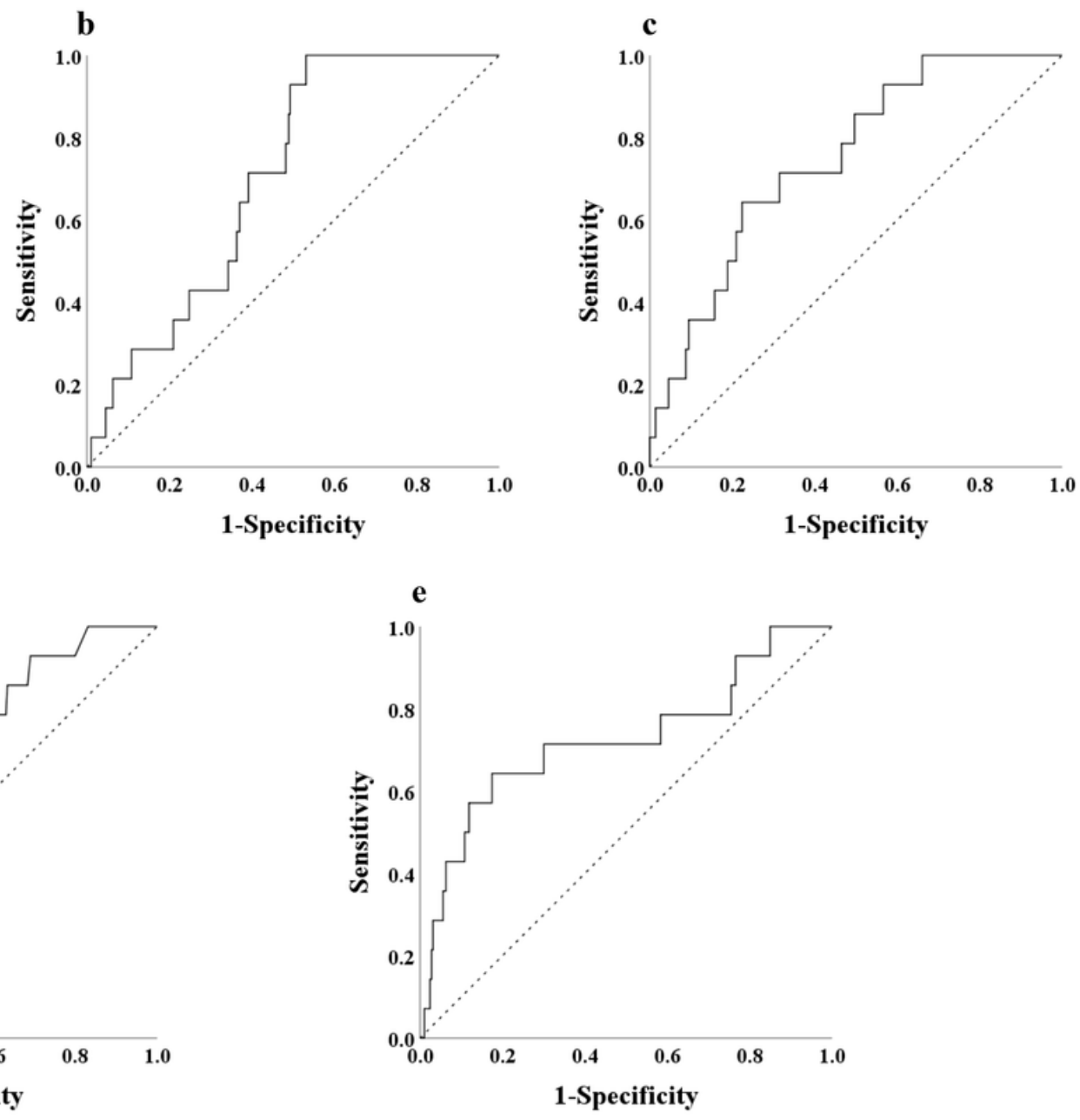

\section{Figure 1}

Evaluation of the relationships between postoperative pneumonia and systemic inflammatory-based prognostic parameters using receiver operating characteristic curves a preoperative NLR, b preoperative PLR, c preoperative $\mathrm{PNI}$, d preoperative CAR, e preoperative LCR.GC, gastric cancer; NLR, preoperative neutrophil-tolymphocyte ratio; PLR, preoperative platelet-to-lymphocyte ratio; PNI, prognostic nutrition index; CAR, Creactive protein-to-albumin ratio; LCR, lymphocyte-to-C-reactive protein ratio 

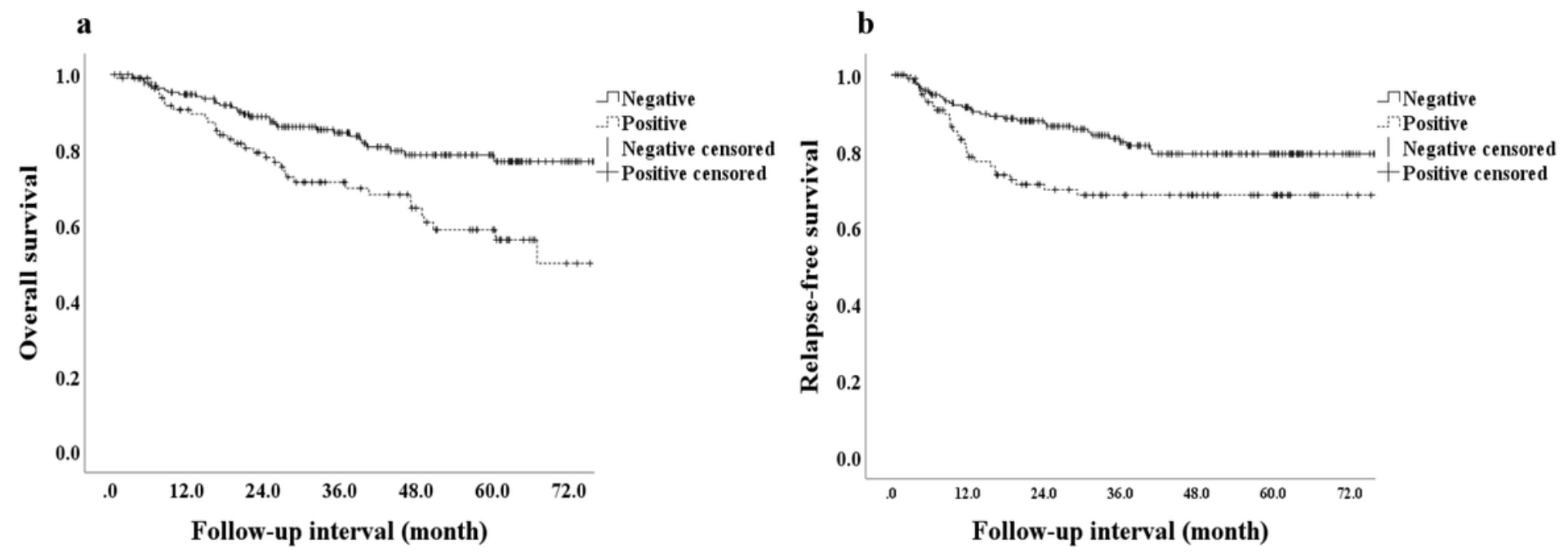

Figure 2

Survival curves with and without any postoperative complication in GC patients, a: overall survival $(P=0.002)$; b: relapse-free survival $(P=0.013)$, using the log-rank test 

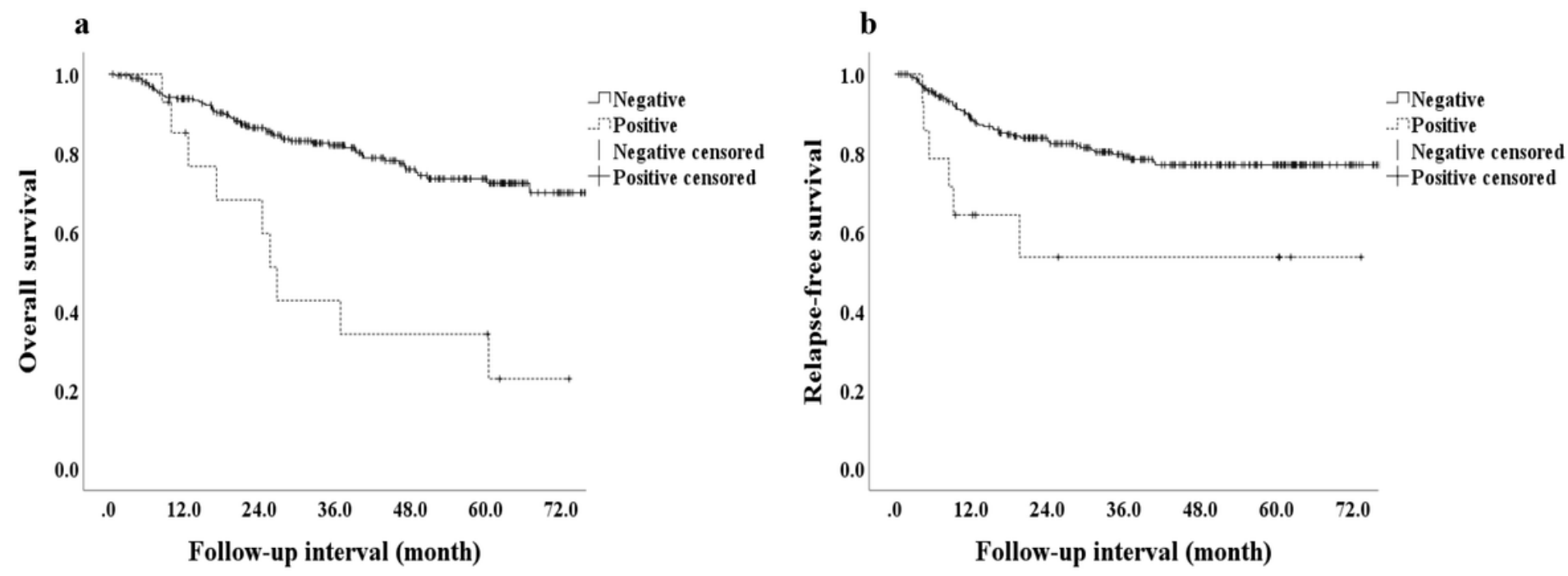

\section{Figure 3}

Survival curves with and without postoperative pneumonia in GC patients, a: overall survival $(P<0.001)$; $b$ : relapse-free survival $(P=0.009)$, using the log-rank test 